\title{
EXPLICATING THE ROLE OF TRUST IN KNOWLEDGE SHARING: A STRUCTURAL EQUATION MODEL TEST
}

\author{
Rasa SMALIUKIENE் ${ }^{1}$, Svajonė BEKEŠIENE் ${ }^{2}$, \\ Eugenijus CHLIVICKAS ${ }^{3}$, Marius MAGYLA ${ }^{4}$
${ }^{1,3}$ Vilnius Gediminas Technical University, Sauletekio al. 11, Vilnius, LT-10223, Lithuania
1,2,4 The General Jonas Žemaitis Military Academy of Lithuania, Department of Engineering Management, Silo g. 5A, Vilnius, LT-10322 Lithuania
E-mails: ${ }^{1}$ rasa.smaliukiene@vgtu.lt (corresponding author); ${ }^{2}$ svajone.bekesiene@lka.lt; 3Eugenijus.Chlivickas@vgtu.lt; ${ }^{4}$ marius.magyla@lka.lt

Received 17 February 2017; accepted 05 April 2017

\begin{abstract}
Although the large body of literature suggests that trust is a prerequisite for knowledge sharing, the understanding of mediational pathways remains limited. The paper fills the gap by combining two separate streams in knowledge sharing, where the first reflects the paradigm of the organizational behaviour theory and highlights the impact of organizational culture and employees' trust; where the second one discloses the impact of technology deployment in knowledge sharing. Building on the premises that interdependence between variables that affect knowledge sharing raises form organizational culture of trust and available technologies, we examine the structural origins of knowledge sharing. As a method structural equation modelling test was used to analyse the data. Hypothesised five-factor model was tested through two stages using AMOS software. The findings carry theoretical implications for the knowledge management body of knowledge since they extended the research on knowledge sharing by integrating organisational culture and technological solutions into one complex system. Form practical perspective, the relationship among four predictors - trust in leadership, trust in co-workers, trust in technologies for knowledge management, and fear of losing one's value - provide a proof on how organizations knowledge sharing is composed and how it could be developed.
\end{abstract}

Keywords: knowledge sharing, culture of trust, structural equation model test, knowledge management, enabling technology, organizational behaviour, social identity theory

JEL Classification: C3, O33, M14.

\section{Introduction}

Throughout the decades trust has been perceived as a precondition for knowledge sharing. Accordingly, a set of technological solutions and managerial measures have been developed to create an efficient environment for this activity. At the beginning it was assumed mainly as a database management (see Matayong, Mahmood 2013) and nowadays - as a wide spreading culture of sharing knowledge and expertise (Chang, Lin 2015). It is confirmed that knowledge sharing allows organization not only to assure a 
continuous flow of significant knowledge but also to retain positive connections within organization (Cano-Kollmann et al. 2016) and its environment (Kwahk, Park 2016). In a broader context, while modern societies are moving fast towards economy of sharing, the interconnection between trust and knowledge sharing in organizations has gained a new level of importance that is analysed in this article.

Despite the fact that a large body of literature suggests that trust is a prerequisite for knowledge sharing, the understanding of mediational pathways in this interconnection remains limited. Thus, this paper fills the gap by combining two separate streams in knowledge sharing, where the first reflects the paradigm of the organizational behaviour theory and highlights the impact of organizational culture and employees' trust; where the second one discloses the impact of technology deployment in knowledge sharing. Building on the premises that interdependence between variables that affect knowledge sharing raise form organizational culture and available technologies, the structural origins of knowledge sharing need to be analysed.

The major goal of this study is to extend previous efforts aimed at developing an integrative model of knowledge sharing. A possible breakthrough rises from the balanced composition of organizational culture and technological solutions for knowledge sharing. Not denying the fact that culture of trust is a condition for the latter (Mueller 2014), technological solutions also need to be addressed as they ensure appropriate storage and dissemination of knowledge within the group and between them (Raudeliūniene et al. 2014). This article extends the attitude towards trust in knowledge sharing. It presents a smart combination of classical elements of trust (as trust in management and co-workers) and trust in technological solutions for knowledge sharing. Building on the premises that interdependence between variables that affect knowledge sharing raises form organizational culture and available technologies, we examine the structural origins of knowledge sharing. Structural interdependence is perceived as a degree to which these three components are interconnected and affect each other in delivering knowledge sharing. Drawing from prior literature, we specify organizational culture as a culture of trust where trust in management and trust in co-workers are interdependent.

The paper proceeds as follows. Firstly, we review existing literature concerning knowledge sharing and develop theoretical frameworks for structural interdependence of knowledge sharing prerequisites. We continue by outlining our research instrument and measurement model. Data are analysed using a covariate structural analysis and findings from a structural equation model test are then presented. Hypothesised five-factor model was tested through two stages using AMOS software. Finally, practical implications are discussed.

\section{Theoretical background and hypothesis development}

Considerable research has been conducted to understand what determines effective knowledge sharing in organizations. One of the most common issues is related to employees' inclination for knowledge sharing. Knowledge sharing is described as a partnership where employees provide others with core knowledge about the processes and outlines (explicit knowledge) as well as share experience and know-how (tacit 
knowledge). Based on this classical distinction, as introduced by Polanyi (1966), the inclination for sharing explicit and tacit knowledge is different. As explicit knowledge is formal and easily recordable, it is perceived as a resource. According to this approach, the personnel must share knowledge as an asset in the process of work (Un, Asakawa 2015), and knowledge management systems are created to support this routine. The challenge arises from tacit knowledge sharing. According to Gubbins and Dooley (2011), tacit knowledge is more valuable as it is more complex and harder to imitate than explicit knowledge. It is also more implicit and intuitive and not expressed directly as well. Knowledge sharing becomes costly and complicated as knowledge coding and sharing gets sophisticated (Evans et al. 2015). Employees share their knowledge by discussing, working together, or even observing each other. Consequently, knowledge sharing cannot be diminished to merely automated procedures of acquisition, storage and dissemination of information. Knowledge sharing is about contextualization, when the "seeker" contacts the "provider" and together creates additional knowledge (Haas et al. 2015). The personnel transfer essential information through social interaction that could be efficiently supported (but not replaced) by information technologies. Accordingly, the researchers developed a process approach of knowledge in organisation which is based on social participation and mutual trust. Following this approach, knowledge is socially constructed and shared in an environment of collaboration and trust.

All kinds of trust are very important, i.e. trust in management and the immediate superior as well as trust in subordinates and co-workers. Knowledge sharing can be improved when people exchange information, best experiences, lessons learned, and insights. Trust in management is one of the main factors influencing employees' decision to share knowledge (Renzl 2008; Pervaiz 2016). Trust is a willingness to be vulnerable (Meyer et al. 2017), and it is strongly associated with the belief that other people will not use this situation for their own benefit. Therefore, trust is a result of two contradicting interactions: on the one hand, there is a fear of losing one's own value; on the other hand, there is desire to collaborate. According to the empirical research, a person's cooperation gets an important role in knowledge sharing which is more likely to occur in a relationship based on trust when an individual is willing to provide the necessary knowledge (Nissen at al. 2014). Trust can be interpreted as willingness to trust or depend on an individual or group. Moreover, an employee sharing knowledge must have trust that the management will see it and award him/her for it (Serenko et al. 2016), may it be an individual or group award which, as a result, would improve group performance (Meyer et al. 2017); therefore, trust in management can enhance knowledge sharing. According to Renzl (2008), trust also enables to concentrate personnel on the task to be carried out in order to create the added value for the organization. Summarizing allegations by various scientists, a direct positive relationship is clearly visible that trust in management is trust in benevolent and trustworthy intentions of the superiors that affect behaviour in the workplace. Following this, we formulated the first hypothesis:

H1: Trust in management fosters the exchange of knowledge.

Not only trust in management, but also in co-workers or team leads to knowledge sharing. Social identity theory answers the majority of questions as to why people tend to share knowledge in groups. Rosendaal and Bijlsma-Frankema (2015) hypothesized that 
the desire to belong to or identify themselves with a group promotes knowledge sharing within it. However, their study showed that the desire itself does not increase knowledge sharing. Only when there is trust within the group, the intensity of knowledge sharing increases (Pinjani, Palvia 2013). From the knowledge management perspective, a trusting person would be more likely to provide useful knowledge to others as trust facilitates effective knowledge sharing. It should be noted that trust does not consist only of people's trust in others, but also of their behaviour and willingness to use knowledge to influence future actions (Chowdhury 2005). Based on the trust and knowledge sharing theory, two principal forms of trust are distinguished: knowledge-based trust, which is based on a person's thinking about trust in others, and effect-based trust, which is based on the emotional connection between people who are related through mutual caring (Renzl 2008). Faith or belief that others will behave thoughtfully is the most important aspect of interpersonal trust which is regarded as one of the essential preconditions for promoting people's decision to share knowledge. Thus, we can formulate the second hypothesis:

\section{H2: Trust in co-workers encourages knowledge sharing.}

Trust in management and trust in co-workers represent positive organizational culture. According to Holste and Fields (2010), the level of trust in management and in coworkers makes an impact to staff members' willingness to share and use knowledge. Therefore, we can hypothesise that trust in management and trust in co-workers are interrelated, i.e. $\mathrm{H} 1 \leftrightarrow \mathrm{H} 2$.

A number of studies reinforce the idea that effective information technology in knowledge management can considerably reduce the impact of trust on knowledge sharing, since person-to-person caused trust (or distrust) diminishes. Technologies represent organisational design variables, such as repositories of knowledge and interrelated formal processes on how knowledge is shared (Chi, Holsapple 2005). This technology-centred approach towards knowledge sharing provides answers on how to create higher trust and to intensify knowledge sharing (Canary, McPhee 2010). For instance, social media is helpful in documenting knowledge in health service where social media tools are used by physicians like a personal notebook to write down and store their professional experiences, lessons learned, or some important information. Therefore, knowledge sharing actually depends on how members of the organization utilize technologies to share knowledge. Information systems and technology help people to share knowledge while creating communities that transcend time and space constraints in the context of knowledge management and increase access to, speed and volume of knowledge (Ignatavičius et al. 2015). The trust in technologies for knowledge management is a white topic in contemporary research literature where the most important elements are trust that the technology can function properly (Kuo 2013) and trust that technology is transparent (Stuermer et al. 2016). In some business contexts, especially in new technology development, trust in technologies also represents the belief that knowledge is safe. As a result, we can formulate the third hypothesis:

H3: Trust in technologies for knowledge management has a positive impact on knowledge sharing. 
One of the strongest factors that reduce knowledge sharing in the organization is the employees' fear of losing their value (Elaimi, Persaud 2014). Analysing the link between the fear of losing the unique value and knowledge sharing, the latter requires considerations: after providing knowledge people can lose their unique value as opposed to others who, as a result, get it. The sharing of knowledge is regarded as weakening an employee's career opportunities especially in hierarchical organisations in countries with a large power distance (Michailova, Husted 2003). In the context of knowledge sharing in large organizations in the information technology, telecommunications or military fields, it is found that knowledge hording is influenced by suspicion (ChinLoy, Mujtaba 2011; Friesl et al. 2011). To add, some extraordinary situations as the announcement of a merger even more increases the fear of losing their status as it is expected that established work norms could change (Empson 2001). Fear of sharing is common not only within organisations but also for internal networks. According to Bøllingtoft (2012), incubated start-ups are reluctant to share their technological knowledge, although they cooperate for access to external sources in order to develop new technologies or test the market opportunities.

On the contrary, companies with well-established accountability-inducing management practices decrease employees' fear of losing their value. Such practices as performance evaluation followed by rewards (Wang et al. 2014) and personal safety, acceptance and inclusion (Raes et al. 2015) could considerably decrease knowledge hording.

The atmosphere of trust existing in organisational culture improves the interpersonal relationships among individuals, promotes knowledge sharing, enables optimal development of knowledge management processes in the organization, makes individuals overcome the trust barrier (people feel valued not because of their knowledge, but because of their skills and desire to share knowledge with others). In addition, trust assuages and may even completely eliminate their fear of losing their value, and, most importantly, it influences their expectations about their co-workers' behaviour in the future (Renzl 2008). In management trust allays employees' fear of being betrayed, cheated or easily replaced as well as losing their unique value (Wasko, Faraj 2005). Accordingly, we can formulate the fourth hypothesis:

H4: Fear of losing one's value in the organization has a negative impact on knowledge sharing.

\section{Method}

We chose the context of the so-called lessons learned and investigated how this type of knowledge is shared within and between teams. The lessons learned approach is widely used in project management, especially in developing new technologies or new products or any kind of operations and experiences in the military. We studied knowledge sharing using the lessons-learned approach in the Lithuanian military forces. Although the formal system of lessons learned consists of the entire process of knowledge management, our study focusses only on knowledge sharing at it is perceived as a part of traditional military culture where the personnel report on lessons after operations or exercises 
(Champoux et al. 2005). To some extent, knowledge sharing in military is similar to any organisation that implements projects or has a knowledge-based framework for its development. The Lithuanian military forces have a formal lessons-learned system that not only includes appropriate standard operating procedures, knowledge compatibility with other NATO partners, but also a net of trained lessons-learned specialists. Individual members of military forces were surveyed in this study to test how knowledge sharing is supported by this organisational structure, culture and technologies.

Structural equation model test was used to testing developed hypotheses and to represent, estimate, and test a theoretical network of relations among observed and latent variables in knowledge sharing. The study is based on hierarchical structural model of knowledge sharing where SPSS AMOS 24 (IBM Corp. 2016) program was used to analyse the model.

\subsection{Measure development and reliability of the construct}

Knowledge sharing (T) is a dependent variable in the model which measures the dissemination of knowledge between (T1) and within teams (T2). The latter (T2) improves team performance (Brown, Calnan 2016) and inspires creativity (Chuang et al. 2016) while the former (T1) increases the efficiency of fulfilment of strategic objectives in the organization (Zhou, Li 2012). Knowledge sharing is associated with four variables and their interrelationships (e):

1. Trust in leadership (five items: L1, L2, L3, L4, L5),

2. Trust in co-workers (three items: K1, K2, K3),

3. Fear of losing one's value (four items: D1, D2, D3, D4),

4. Knowledge documentation (four items: P1, P2, P3, P4).

Trust in management (L) was measured using three positive elements: (1) the superior understands subordinates, (2) the superior motivates subordinates to use lessons learned, (3) superiors behave correctly with subordinates; and two negative elements: (4) superiors exploit subordinates, (5) superiors discipline and punish subordinates for their mistakes (Table 1).

Trust in co-workers (K) was measured using three elements: (1) their desire to help when faced with difficulties, (2) their ability to help when faced with difficulties, (3) trust in their promises.

Trust in technologies for knowledge management $(\mathrm{P})$ represents not only an attitude towards the technologies used, but also the trust in the institution in general. Knowledge preservation and sharing was measured by subjective perception "properly". "Properly" in our case means the level of acceptability of institutional procedures and techniques to keep and share knowledge. It also reflects the level to which knowledge exploration involves opportunities for knowledge re-usage in new situations (Canary, McPhee 2010). In a military context, technologies must provide information at the right time to the right person. Consequently, "proper" technologies are capable of disseminating knowledge at the time of the request (Champoux et al. 2005) which in the military context is of the highest priority. Trust in technologies for knowledge management is this study was measured by four elements where two of them represent the properness of knowledge preservation and sharing within the unit and the other two - between the units. 
Table 1 . The research construct data and construct reliability

\begin{tabular}{|c|c|c|c|c|}
\hline $\begin{array}{c}\text { Latent } \\
\text { variables }\end{array}$ & Measurement indicators & Coding & $\begin{array}{l}\text { Factor } \\
\text { loading }\end{array}$ & $\begin{array}{l}\text { Cronbach's } \\
\text { Alpha }\end{array}$ \\
\hline \multirow{2}{*}{$\begin{array}{l}\text { Knowledge } \\
\text { sharing (T) }\end{array}$} & Sharing of the lessons learned in an organization & $\mathrm{T} 1$ & 0.887 & \multirow{2}{*}{0.830} \\
\hline & Sharing of lessons learned in an unit & $\mathrm{T} 2$ & 0.843 & \\
\hline \multirow{5}{*}{$\begin{array}{l}\text { Trust in } \\
\text { leadership } \\
\text { (L) }\end{array}$} & Managers promote the usage of lessons learned & L1 & 0.630 & \multirow{4}{*}{0.797} \\
\hline & $\begin{array}{l}\text { Immediate manager understands situation of } \\
\text { subordinates / employees perspective }\end{array}$ & L2 & 0.534 & \\
\hline & The organization treats employees fairly & L3 & 0.766 & \\
\hline & $\begin{array}{l}\text { Immediate manager exploits his subordinates } \\
\text { (negative) }\end{array}$ & L4 & 0.741 & \\
\hline & Immediate manager/commander chastise for mistakes & L5 & 0.765 & \multirow{4}{*}{0.872} \\
\hline \multirow{3}{*}{$\begin{array}{l}\text { Trust in co- } \\
\text { workers }(\mathrm{K})\end{array}$} & Colleagues are able to help & K1 & 0.816 & \\
\hline & Colleagues are going to help if needed & $\mathrm{K} 2$ & 0.910 & \\
\hline & Colleagues are going to do what they have promised & $\mathrm{K} 3$ & 0.853 & \\
\hline \multirow{4}{*}{$\begin{array}{l}\text { Trust in } \\
\text { technologies } \\
\text { for } \\
\text { knowledge } \\
\text { management } \\
\text { (P) }\end{array}$} & $\begin{array}{l}\text { Knowledge (lessons learned) is preserved properly } \\
\text { in the unit. }\end{array}$ & $\mathrm{P} 1$ & 0.745 & \multirow{4}{*}{0.746} \\
\hline & $\begin{array}{l}\text { Knowledge (lessons learned) is preserved properly } \\
\text { in the organization. }\end{array}$ & $\mathrm{P} 2$ & 0.777 & \\
\hline & $\begin{array}{l}\text { Knowledge (lessons learned) is shared properly } \\
\text { in the unit. }\end{array}$ & P3 & 0.792 & \\
\hline & $\begin{array}{l}\text { Knowledge (lessons learned) is shared properly } \\
\text { in the organization. }\end{array}$ & P4 & 0.677 & \\
\hline \multirow{4}{*}{$\begin{array}{l}\text { Fear of } \\
\text { losing one's } \\
\text { value (D) }\end{array}$} & $\begin{array}{l}\text { Knowledge sharing does not add additional value } \\
\text { for my job evaluation. }\end{array}$ & D1 & 0.769 & \multirow{4}{*}{0.713} \\
\hline & $\begin{array}{l}\text { Knowledge sharing depreciates my value in the } \\
\text { organization }\end{array}$ & D2 & 0.7863 & \\
\hline & $\begin{array}{l}\text { Knowledge are vulnerable to loss their value when } \\
\text { sharing }\end{array}$ & D3 & 0.876 & \\
\hline & Knowledge sharing leads to the loss of advantage & D4 & 0.672 & \\
\hline
\end{tabular}

In addition to the measures on trust, our research construct is complemented with a variable of fear. Fear of losing one's value (D) was measured using two elements: (1) the reward for sharing knowledge, (2) the status after sharing knowledge. These elements in the questionnaire got four questions. Knowledge documentation $(\mathrm{P})$ was measured using four elements: (1) quality of knowledge documentation, (2) accessibility of knowledge. The elements in the questionnaire were also broken down into four questions in order to measure knowledge sharing between and within teams.

The theoretical framework was first tested by the qualitative research. Interviews with experts detected the main problem areas in terms of knowledge sharing. External validity of the model was approved as a result. Respondents were asked to answer questions in relation to trust in their management and co-workers, fear of losing their value in the organization by sharing their knowledge as well as knowledge documentation in 
their unit. Last 7 questions reflect the demographic and social characteristics such as gender, age, education, military rank, length of service, served years in a specific unit and place of service. The questionnaire consists of 26 questions. Most of the questions are evaluated using a five-point scale.

\subsection{Sample and data collection}

To test our hypothesis, we collected data from two functionally similar military units and in order to obtain objective results, which would show the situation in the context of knowledge management, only professional soldiers, who have or still serve in Lithuanian armed forces and face managerial processes (setting goals, planning, organization, control, and evaluation), were given the questionnaire. It was a general population survey (N 526 military personnel), and 108 fully completed self-administrative questionnaires were returned. The response rate was $20 \%$ and this was an appropriate response level in comparison to similar surveys.

Respondents were asked to provide demographic information including the length of service in Lithuanian armed forces, the length of service in the unit, military rank, education, age, and gender. Most of the respondents were male (91\%) from 26 to 47 years old. $6 \%$ of the respondents were privates, $31 \%$ - sergeants, $53 \%$ - junior officers and $11 \%$ - senior officers. Higher education was obtained by $94 \%$, and $92 \%$ of the respondents have served for more than 6 years. Thus, the respondents were experienced, had proper knowledge and military ranks and they were familiar with knowledge management processes in the organization.

\section{Analysis}

Structural equation modelling (SEM) technique was used to test the research model. SEM is a comprehensive approach for hypothesis testing and can be used for predictive applications testing (Byrne 2013). The modelling is based on path analysis, factor analysis, and linear regression, it also analysis latent constructs and measurable variables of the theoretical causal model. In our case the model consists of five exogenous variables $(\mathrm{H} 1, \mathrm{H} 2)$ and three endogenous variables $(\mathrm{H} 3, \mathrm{H} 4$, and $\mathrm{T})$. A confirmatory factor analysis of scales and the estimation of fit were performed using SPSS AMOS. Before analysing the theoretical framework, the questionnaire was assessed to evaluate how the questions (variables) would reflect the latent factors. Cronbach's alpha (hereinafter - CA) coefficient is a very popular coefficient to test reliability (Bollen, Long 1993; Garson 2012). So the CA coefficient, which is based on the correlation of individual questions that make up the questionnaire, was used to evaluate the internal consistency of the questionnaire's scales. By the rule, CA coefficient of a well prepared questionnaire has to be higher than 0.7 . The calculated CA coefficients for all questions are presented in Table 1.

Confirmatory factor analysis (CFA) using the AMOS 24 program was applied to additional confirmation of construct validity of items and of constructs used in the main study. CFA was conducted to estimate factor loadings of variables, which presents the level of a regression path from a latent to its indicators. In this study, the five latent vari- 
ables had different number of indicators (the questionnaire items). So we tested factors loading values and followed the rule, which explains that path coefficient measurement has to be more than 0.5 ; when coefficient is equal to 0.7 or above it indicates perfect set of variables (Hair et al. 2012).

The validity of measurement model depends on the levels of goodness-of-fit for the measurement model and provides specific evidence of construct validity. In this research model construct refers to a complex concept which includes several interrelated factors. To test the construct validity, which shows a theoretical viewpoint (Wiersma 2000), the convergent validity method was used. In this study, convergent validity was assessed by factor loadings, Composite Reliability (CR) and Average Variance Extracted (AVE) (Hair et al. 2012).

\subsection{First run of the measurement model}

Confirmatory factor analysis (CFA) was chosen to test the hypothesized model because the model's latent variables were constructed accordingly to theory and they already existed in theoretical models of previous studies (Brown, Calnan 2016; Carmeli et al. 2011).The tested hypothesized model consisted of 4 latent variables and 16 indicators, 20 measurement error associated with variables and indicators, one factor being predicted by 2 indicators, all together 43 distinct parameter were estimated (Fig. 1). The model was evaluated by statistical means to determine the adequacy of its goodness-of-fit.

Statistical significance of parameters estimates is presented in Table 2. Critical ratio (C.R.) of covariance does not exceed \pm 1.96 therefore all parameters are not considered as important in the model because all p values are higher than 0.05 .

Standardized residuals covariances also indicate that there is no significant discrepancy between the covariance matrix that is implied by the hypothesized model, and the sample covariance matrix. A lot of measures of the Standardized residuals covariances were too great and approximately equal to 2 (Appendix Table A1).

Moreover, the other indicators, which are computed to check the goodness-of-fit of the hypothesized model indicated mediocre to poor fit (Hypothesised Model in Table 3). The literature suggests using chi-square value with moderate samples. As our sample was 108 , we followed this recommendation. Chi-square value of our test was 186.325 with very low probability $\left(\mathrm{df}=128, \mathrm{p}=0.001 ; \chi^{2} / \mathrm{df}=1.456\right)$. Additionally to $\chi^{2}$ test, more pragmatic goodness-of-fit indices were used. Root mean square residual $(\mathrm{RMR}=$ 0.156 ) is bigger than 0.05 and represents "big discrepancy between the sample observed and hypothesized correlation matrices" (Byrne 2013: 77). The Goodness-of-Fit Index $(\mathrm{GFI}=0.659)$ and Adjusted Goodness-of-Fit Index $(\mathrm{AGFI}=0.544)$ represent the average fit of the model, as are not close to 1.00. Parsimony Goodness-of-Fit Index $(\mathrm{PGFI}=0.493)$ addresses the complexity of the hypothesized model and, as expected for nonsignificant $\chi^{2}$ statistics, indicates pure fit of the model. Root mean square error of approximation $(\mathrm{RMSEA}=0.114$ ) was one of the most informative criteria in model measurement it indicates poor fit. In summarizing goodness-of fit statistic for hypothesised model we can see that they reflect an ill-fitting model. It is evident that some changes in model are needed in order to identify a model of trust in knowledge sharing for the sample data. 


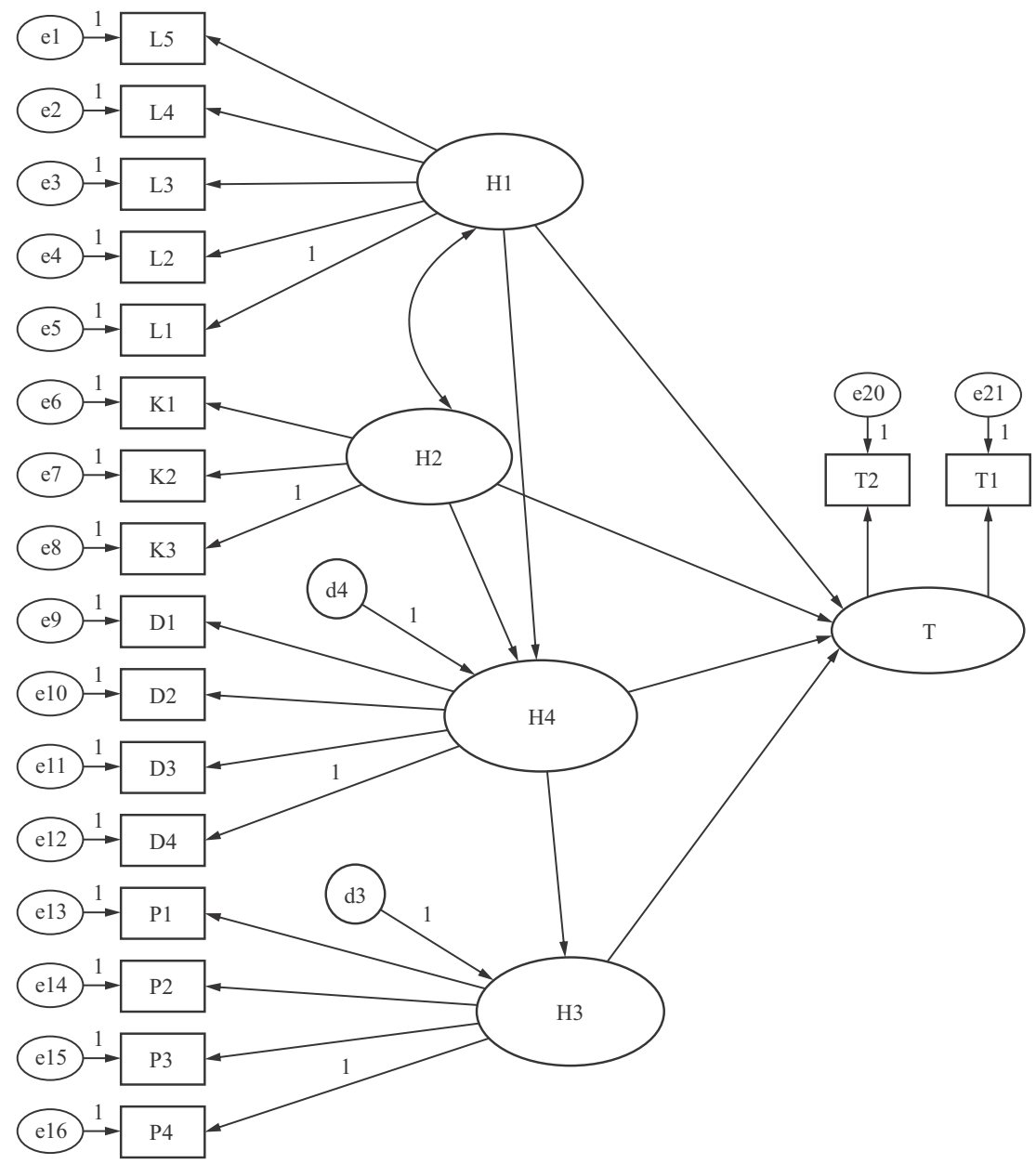

Fig.1. Hypothesized model's factorial structure

Table 2. Hypothesized five-factor CFA model: parameter estimates

\begin{tabular}{ccccccc}
\hline \multicolumn{2}{c}{ Relationship } & Factor loading & S.E. & C.R. & P \\
\hline $\mathrm{H} 4$ & $\leftarrow$ & $\mathrm{H} 1$ & -1.750 & 1.257 & -1.392 & 0.164 \\
\hline $\mathrm{H} 4$ & $\leftarrow$ & $\mathrm{H} 2$ & 1.600 & 0.955 & 1.675 & 0.094 \\
\hline $\mathrm{H} 3$ & $\leftarrow$ & $\mathrm{H} 4$ & -0.378 & 0.293 & -1.287 & 0.198 \\
\hline $\mathrm{T}$ & $\leftarrow$ & $\mathrm{H} 1$ & 0.933 & 0.694 & 1.344 & 0.179 \\
\hline $\mathrm{T}$ & $\leftarrow$ & $\mathrm{H} 4$ & 0.378 & 0.293 & 1.293 & 0.196 \\
\hline $\mathrm{T}$ & $\leftarrow$ & $\mathrm{H} 3$ & 0.094 & 0.105 & 0.901 & 0.367 \\
\hline $\mathrm{T}$ & $\leftarrow$ & $\mathrm{H} 2$ & -0.825 & 0.565 & -1.461 & 0.144 \\
\hline
\end{tabular}


Table 3. Goodness-of-fit statistics of the hypothesised and respecified models

\begin{tabular}{lccc}
\hline \multicolumn{1}{c}{ Fit Index } & $\begin{array}{c}\text { Recommended value } \\
\text { (Hair } \text { et al. 2012) }\end{array}$ & $\begin{array}{c}\text { Hypothesised } \\
\text { Model }\end{array}$ & $\begin{array}{c}\text { Respecified } \\
\text { Model }\end{array}$ \\
\hline$\chi 2 /$ df & $\leq 3$ & 1.456 & 1.169 \\
\hline Probability level & $>0.05$ & 0.001 & 0.099 \\
\hline RMSEA & $\leq 0.08$ & 0.114 & 0.069 \\
\hline GFI & $\geq 0.9$ & 0.659 & 0.734 \\
\hline RMR & $<0.5$ & 0.156 & 0.139 \\
\hline NFI & $\geq 0.9$ & 0.512 & 0.630 \\
\hline CFI & $\geq 0.9$ & 0.745 & 0.911 \\
\hline TLI & $\geq 0.9$ & 0.695 & 0.887 \\
\hline PNFI & The higher, the better & 0.428 & 0.498 \\
\hline
\end{tabular}

\subsection{Modification indices}

Following the body of literature on leadership and leadership in knowledge sharing we added additional covariances to the hypothesised model. As it was already hypothesised in theoretical background of this article, trust in leadership and trust in co-workers are interrelated and their interplay creates culture of trust in the organization. This interplay we identified as a covariance between $\mathrm{H} 1$ and $\mathrm{H} 2$ in our respecified model. Structural equation modelling provides a unique approach towards variance and measurement errors interdependence therefore we developed a respecified (nested) model (Saris, Revilla 2016). In the hypothesised model variables and measurement errors are random and unique (uncorrelated between selfs), whereas the respecified model reframes an originally hypothesized model and represents covariances or correlations between measurement errors. Following methodological guidelines of structural equation modelling to "add only one parameter at a time to the model" (Byrne 2013: 112), using goodnessto-fit statistics and the modification indices for each parameter, which were computed by SEM, we estimated covariance within measurement errors of trust in leadership $(\mathrm{e} 1 \leftrightarrow \mathrm{e} 2, \mathrm{e} 1 \leftrightarrow \mathrm{e} 3)$ and between indicators of trust in leadership and trust in co-workers (e4↔e6) (Table 4).

Table 4. Modification indices for hypothesised model correction

\begin{tabular}{ccccc}
\hline & Covariances & & M.I. & Par Change \\
\hline $\mathrm{e} 6$ & $\leftrightarrow$ & $\mathrm{d} 4$ & 5.475 & 0.069 \\
\hline $\mathrm{e} 14$ & $\leftrightarrow$ & $\mathrm{e} 8$ & 4.857 & 0.195 \\
\hline $\mathrm{e} 16$ & $\leftrightarrow$ & $\mathrm{d} 4$ & 5.018 & 0.145 \\
\hline $\mathrm{e} 2$ & $\leftrightarrow$ & $\mathrm{e} 1$ & 9.499 & 0.370 \\
\hline $\mathrm{e} 3$ & $\leftrightarrow$ & $\mathrm{e} 16$ & 4.496 & 0.504 \\
\hline $\mathrm{e} 3$ & $\leftrightarrow$ & $\mathrm{e} 1$ & 8.838 & 0.600 \\
\hline $\mathrm{e} 3$ & $\leftrightarrow$ & $\mathrm{e} 2$ & 5.189 & 0.346 \\
\hline $\mathrm{e} 4$ & $\leftrightarrow$ & $\mathrm{e} 20$ & 5.082 & -0.163 \\
\hline $\mathrm{e} 4$ & $\leftrightarrow$ & $\mathrm{e} 14$ & 5.930 & 0.242 \\
\hline
\end{tabular}


In align with the discussion from previous research on leadership we estimated one covariance between measurement errors of trust in leadership and fear of losing one's value (e3↔e9) and three covariances between trust in leadership and knowledge documentation $(\mathrm{e} 3 \leftrightarrow \mathrm{e} 13, \mathrm{e} 4 \leftrightarrow \mathrm{e} 14, \mathrm{e} 4 \leftrightarrow \mathrm{e} 16)$. The statistic of covariation is presented in Table 5.

Table 5. Modifications indices in the second run

\begin{tabular}{ccccccc}
\hline \multicolumn{2}{c}{ Relationship } & Estimate & S.E. & C.R. & P \\
\hline $\mathrm{H} 1$ & $\leftrightarrow$ & $\mathrm{H} 2$ & 0.294 & 0.103 & 2.865 & 0.004 \\
\hline $\mathrm{e} 2$ & $\leftrightarrow$ & e1 & 0.261 & 0.119 & 2.192 & 0.028 \\
\hline e3 & $\leftrightarrow$ & e1 & 0.447 & 0.173 & 2.583 & 0.010 \\
\hline e4 & $\leftrightarrow$ & e14 & 0.280 & 0.114 & 2.463 & 0.014 \\
\hline e4 & $\leftrightarrow$ & e16 & -0.184 & 0.121 & -1.529 & 0.126 \\
\hline e4 & $\leftrightarrow$ & e6 & -0.070 & 0.053 & -1.320 & 0.187 \\
\hline e3 & $\leftrightarrow$ & e13 & -0.384 & 0.148 & -2.601 & 0.009 \\
\hline e3 & $\leftrightarrow$ & e9 & 0.219 & 0.089 & 2.450 & 0.014 \\
\hline
\end{tabular}

\subsection{Second run of the measurement model}

The respecified model consisted of 50 parameters where 7 additional parameters to the originally hypothesized model were added. Goodness-of-fit statistics related to the respecified model reported that incorporation of the error covariance between items made a substantial improvement in model fit (Respecified Model in Table 6). The probability level increased to 0.099 . This finding suggests that model fits the data acceptably in the population. Accordingly, chi-square $(\chi 2)$ decreased from 186.325 to 141.39 and RMSEA from 0.114 to 0.069 . RMSEA is recognized as one of the most informative criteria in the model fit evaluating. According to Schreiber et al. (2006) the RMSEA value of 0.06 indicates a good model fit. Now all other Goodness-of-fit indices were enhanced to good. Factor loadings provided by AMOS are presented in Table 6. Based on all these indicators as well as on goodness-of-fit statistics, the theoretical model considered to be valid.

Theoretical five-factor model demonstrate reliability and factor stability. Figure 2 shows the results of the test structural model. Based on the analysis, trust in leadership is the strongest predictor of knowledge sharing $(\beta=0.52, \mathrm{p}=0.267)$. This finding is aligned with the insights from previous analysis where leadership was found to result greater knowledge sharing (e.g. Carmeli et al. 2011). Accordingly, knowledge sharing is positively influenced by trust in co-workers $(\beta=-0.377 ; \mathrm{p}=0.265)$, detailed documentation of knowledge $(\beta=0.128 ; p=0.239)$, whereas fear of losing one's value in the organization has a negative impact on knowledge sharing $(\beta=0.238 ; p=0.264)$. In addition, the standardized factor loading showed the acceptable level $(>0.5)$ on all items on their constructs. To test the convergent validity factor loading, average variance extracted (AVE) and composite reliability (CR) were checked (Table 7). 
Table 6. Respecified five-factor CFA model: parameter estimates

\begin{tabular}{|c|c|c|c|c|c|c|}
\hline \multicolumn{3}{|c|}{ Relationship } & \multirow{2}{*}{$\frac{\text { Estimate }}{0.805}$} & \multirow{2}{*}{$\begin{array}{c}\text { S.E. } \\
0.539\end{array}$} & \multirow{2}{*}{$\begin{array}{c}\text { C.R. } \\
1.494\end{array}$} & \multirow{2}{*}{$\frac{\mathrm{P}}{0.135}$} \\
\hline $\mathrm{H} 4$ & $\leftarrow$ & $\mathrm{H} 2$ & & & & \\
\hline $\mathrm{H} 4$ & $\leftarrow$ & H1 & -0.962 & 0.747 & -1.287 & 0.198 \\
\hline $\mathrm{H} 3$ & $\leftarrow$ & $\mathrm{H} 4$ & -0.352 & 0.268 & -1.309 & 0.190 \\
\hline $\mathrm{T}$ & $\leftarrow$ & H1 & 0.524 & 0.473 & 1.109 & 0.267 \\
\hline $\mathrm{T}$ & $\leftarrow$ & $\mathrm{H} 4$ & 0.238 & 0.213 & 1.118 & 0.264 \\
\hline $\mathrm{T}$ & $\leftarrow$ & H3 & 0.128 & 0.108 & 1.177 & 0.239 \\
\hline $\mathrm{T}$ & $\leftarrow$ & $\mathrm{H} 2$ & -0.377 & 0.339 & -1.114 & 0.265 \\
\hline L4 & $\leftarrow$ & H1 & 0.824 & 0.332 & 2.482 & 0.013 \\
\hline L3 & $\leftarrow$ & H1 & 1.000 & & & \\
\hline L5 & $\leftarrow$ & H1 & -0.049 & 0.351 & -0.139 & 0.889 \\
\hline L2 & $\leftarrow$ & H1 & 1.112 & 0.276 & 4.024 & $* * *$ \\
\hline $\mathrm{L} 1$ & $\leftarrow$ & H1 & 0.597 & 0.306 & 1.948 & 0.051 \\
\hline D1 & $\leftarrow$ & $\mathrm{H} 4$ & 1.000 & & & \\
\hline D2 & $\leftarrow$ & $\mathrm{H} 4$ & 0.371 & 0.142 & 2.614 & 0.009 \\
\hline D3 & $\leftarrow$ & $\mathrm{H} 4$ & 0.889 & 0.328 & 2.709 & 0.007 \\
\hline D4 & $\leftarrow$ & $\mathrm{H} 4$ & 0.425 & 0.179 & 2.379 & 0.017 \\
\hline $\mathrm{P} 4$ & $\leftarrow$ & $\mathrm{H} 3$ & 1.000 & & & \\
\hline $\mathrm{P} 3$ & $\leftarrow$ & $\mathrm{H} 3$ & 1.208 & 0.409 & 2.957 & 0.003 \\
\hline $\mathrm{P} 2$ & $\leftarrow$ & $\mathrm{H} 3$ & 1.143 & 0.364 & 3.137 & 0.002 \\
\hline P1 & $\leftarrow$ & H3 & 0.683 & 0.251 & 2.722 & 0.006 \\
\hline K3 & $\leftarrow$ & $\mathrm{H} 2$ & 0.650 & 0.141 & 4.613 & $* * *$ \\
\hline K2 & $\leftarrow$ & $\mathrm{H} 2$ & 1.251 & 0.191 & 6.545 & $* * *$ \\
\hline K1 & $\leftarrow$ & $\mathrm{H} 2$ & 1.000 & & & \\
\hline $\mathrm{T} 2$ & $\leftarrow$ & $\mathrm{T}$ & 1.000 & & & \\
\hline $\mathrm{T} 1$ & $\leftarrow$ & $\mathrm{T}$ & 5.440 & 4.114 & 1.322 & 0.186 \\
\hline
\end{tabular}

Note: *** Significant at the $1 \%$ level

Furthermore, the establishing discriminant validity, which requires an appropriate AVE (Average Variance Extracted) analysis was done by comparing AVE of each variable with the construct correlation. The square root of every AVE for each construct was much larger than any correlation among any pair of latent construct. All AVE by the rule (Hair et al. 2012) were greater than 0.5 (Table 8). The construct correlations are presented in Table 8 . The diagonal items in the table characterise the square root of AVE's, which is a measure of variance between construct and its indicators. The results of testing convergent validity and discriminant validity revealed a good construct validity and reliability (Fig. 2). 
Table 7. Reliabilities and convergent validity of constructs of the proved model

\begin{tabular}{|c|c|c|c|c|c|}
\hline Construct & Items & Factor loading & Cronbach's Alpha & $\mathrm{CR}$ & AVE \\
\hline \multirow{2}{*}{ Knowledge sharing $(\mathrm{T})$} & T1 & 0.224 & \multirow{2}{*}{0.830} & \multirow{2}{*}{0.604} & \multirow{2}{*}{0.718} \\
\hline & $\mathrm{T} 2$ & 0.991 & & & \\
\hline \multirow{5}{*}{ Trust in leadership (H1) } & L1 & 0.500 & \multirow{5}{*}{0.797} & \multirow{5}{*}{0.722} & \multirow{5}{*}{0.588} \\
\hline & L2 & 0.705 & & & \\
\hline & L3 & 0.521 & & & \\
\hline & L4 & 0.653 & & & \\
\hline & L5 & 0.535 & & & \\
\hline \multirow{3}{*}{ Trust in co-workers $(\mathrm{H} 2)$} & K1 & 0.790 & \multirow{3}{*}{0.872} & \multirow{3}{*}{0.878} & \multirow{3}{*}{0.844} \\
\hline & $\mathrm{K} 2$ & 1.016 & & & \\
\hline & K3 & 0.692 & & & \\
\hline \multirow{4}{*}{ Knowledge documentation (H3) } & $\mathrm{P} 1$ & 0.582 & \multirow{4}{*}{0.746} & \multirow{4}{*}{0.741} & \multirow{4}{*}{0.647} \\
\hline & P2 & 0.710 & & & \\
\hline & P3 & 0.665 & & & \\
\hline & $\mathrm{P} 4$ & 0.624 & & & \\
\hline \multirow{4}{*}{ Fear of losing one's value (H4) } & D1 & 0.470 & \multirow{4}{*}{0.713} & \multirow{4}{*}{0.777} & \multirow{4}{*}{0.693} \\
\hline & D2 & 0.781 & & & \\
\hline & D3 & 0.879 & & & \\
\hline & D4 & 0.563 & & & \\
\hline
\end{tabular}

Table 8. Reliabilities and convergent validity of constructs of the proved model

\begin{tabular}{cccccc}
\hline & $\mathrm{H} 2$ & $\mathrm{H} 1$ & $\mathrm{H} 4$ & $\mathrm{H} 3$ & $\mathrm{~T}$ \\
\hline $\mathrm{H} 2$ & 0.844 & & & & \\
\hline $\mathrm{H} 1$ & 0.773 & 0.588 & & & \\
\hline $\mathrm{H} 4$ & 0.230 & -0.125 & 0.693 & & \\
\hline $\mathrm{H} 3$ & -0.072 & 0.039 & -0.314 & 0.647 & \\
\hline $\mathrm{T}$ & -0.069 & 0.339 & 0.198 & 0.412 & 0.718 \\
\hline
\end{tabular}

Note: Square root of AVE is on the diagonal

\section{Conclusions and implications}

In this study, we explore the impact of trust on knowledge sharing where technological solutions and managerial measures were analysed. Our research results provide theoretical implications and enhance the existing literature on knowledge sharing in three primary ways.

Firstly, knowledge sharing is perceived as a complex phenomenon where organizational culture and technological solutions are interdepended. Our implication is related to the entire knowledge sharing model. Our research results supported this integrative 


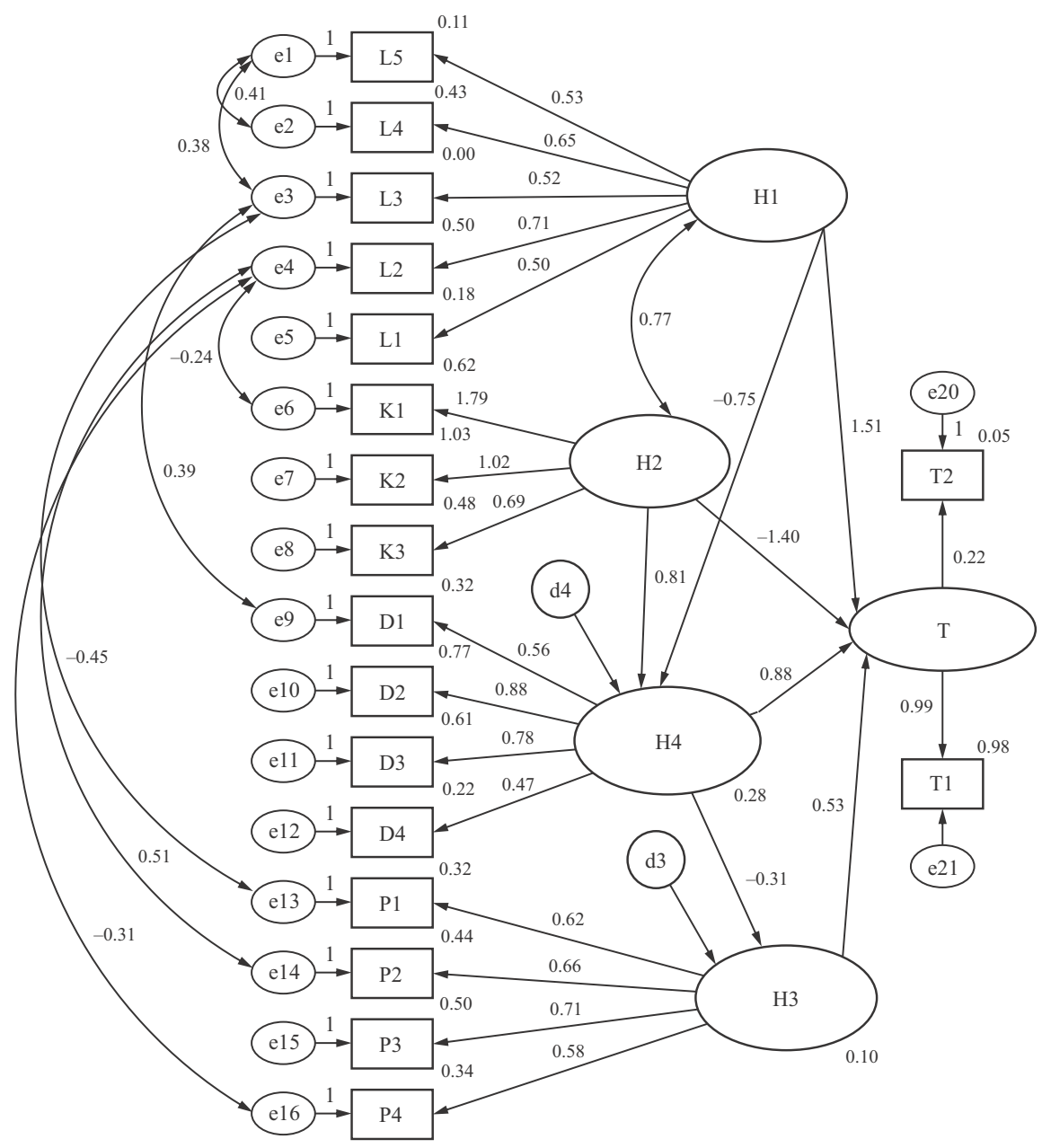

Fig.2. Structural model $(* * \mathrm{p}<0.01 ; * * * \mathrm{p}<0.001)$

model of trust - knowledge sharing. This study went beyond prior research and showed that knowledge sharing has four predictors (i.e. trust in leadership, trust in co-workers, knowledge storing, and fear of losing one's value). Thus, our model identifies the mediational pathways that link in to a loop all four predictors. The present results suggest that trust in leadership and trust in co-workers may reduce a fear of losing one's value, but has no direct impact on knowledge storing. To sum up, our model and findings provide a new understanding of the relation between trust and knowledge sharing where information storing plays not the vital, but important role.

Secondly, the results contribute to explicating and highlighting the role of trust in management when sharing knowledge. Organisational culture set by the organisation authority makes the biggest contribution by dispelling fear as the main barrier in knowledge sharing. According to the study results, elements of organizational culture (trust in 
management and co-workers) are more important than technical solutions of knowledge management. Despite the fact that organizations develop knowledge management systems and invest in IT solutions to support them, organizational culture is of the utmost importance when it comes to knowledge sharing. According to our confirmed hypothesis, trust in management and co-workers encourages to share knowledge as employees tend to share it if the superiors are able to look at the situation from the perspective of subordinates and vice versa, and avoid doing that if the management disciplines them for their mistakes. This is especially important for organizations subject to the principle of lessons learned which are considered as mistakes that in order to be acknowledged require the environment based on trust created by the superiors. As previous research showed there is a lessons learned paradox, i.e. despite the large number of lessons learned, they do not become knowledge that would be shared in organizations. One of the main reasons for this paradox is the inability of superiors to create a mistake-tolerant work environment. However, the direct impact by the superiors on knowledge sharing should not be overestimated. Equally important is the organization's microclimate within the team. Our study results confirmed that the fear of losing one's value can equally be heightened by both superiors and co-workers. Additionally, trust within a team influences the intensity and level of relations in the team as well as the determination to share knowledge.

The last implication involves the confirmation that knowledge sharing is a cognitive process where a fair exchange plays a vital role. According to the commitment-trust theory, trust and commitment are not only the basis for good relations but also a condition for long-term effective exchange among the organization members. It is a fair exchange principle (whether I will be properly rewarded) that determines the decision to share knowledge. Our study confirmed that subordinates who think that they will not be rewarded for sharing knowledge have no trust in management and, accordingly, are not inclined to share knowledge.

\section{Limitations}

Despite the comprehensiveness of the present study, a few limitations need to be noted. Firstly, results are based on a specific sample of military personnel. The hierarchical structure of the organisation and standardised procedures for knowledge sharing could have had an impact on the research results, but the main findings are applicable for non-statutory large organisations where a knowledge-based framework for the development is implemented. From previous research, it is recalled that military as a research object shows similar results as other hierarchical organisations in terms of the fear of losing one's value. Secondly, the research sample was relatively small. Although CFI is not very sensitive to small samples, this study could be cross-validated, especially after taking the sample from non-statutory organizations. Thirdly, an opinion survey was the only data source used for this study which followed the tradition in knowledge management research practice. However, the opinion survey data supplemented by the performance data could give more comprehensive research results and avoid opinion measurement errors that can occur in surveys. 


\section{References}

Bollen, K. A.; Long, J. S. 1993. Testing structural equation models. Vol. 154. Sage.

Bøllingtoft, A. 2012, The bottom-up business incubator: leverage to networking and cooperation practices in a self-generated, entrepreneurial-enabled environment, Technovation 32(5): 304-315. https://doi.org/10.1016/j.technovation.2011.11.005

Brown, P. R.; Calnan, M. W. 2016. Chains of (dis) trust: exploring the underpinnings of knowledge-sharing and quality care across mental health services, Sociology of Health \& Ilness 38(2): 286-305. https://doi.org/10.1111/1467-9566.12369

Byrne, B. M. 2013. Structural equation modeling with AMOS: basic concepts, applications, and programming. Routledge.

Champoux, P.; Costello, M. J.; Bourget, S. 2005. The Canadian knowledge management system (KMS) within the land force command and control information systems (LFC2IS), [online], [cited 25 March 2017], in 10th International Command and Control Research and Technology Symposium, 13-16 June 2005, McLean, Virginia. Available from Internet: www.dodccrp.org/ events/10th_ICCRTS/CD/papers/198.pdf

Canary, H. E.; McPhee, R. D. (Eds.). 2010. Communication and organizational knowledge: contemporary issues for theory and practice. Routledge.

Cano-Kollmann, M.; Cantwell, J.; Hannigan, T. J.; Mudambi, R.; Song, J. 2016. Knowledge connectivity: an agenda for innovation research in international business, Journal of International Business Studies 47(3): 255-262. https://doi.org/10.1057/jibs.2016.8

Carmeli, A.; Atwater, L.; Levi, A. 2011. How leadership enhances employees' knowledge sharing: the intervening roles of relational and organizational identification, The Journal of Technology Transfer 36(3): 257-274. https://doi.org/10.1007/s10961-010-9154-y

Chang, C. L. H.; Lin, T. C. 2015. The role of organizational culture in the knowledge management process, Journal of Knowledge Management 19(3): 433-455.

https://doi.org/10.1108/JKM-08-2014-0353

Chi, L.; Holsapple, C. W. 2005. Understanding computer-mediated interorganizational collaboration: a model and framework, Journal of Knowledge Management 9(1): 53-75. https://doi.org/10.1108/13673270510582965

Chin-Loy, C.; Mujtaba, B. G. 2011. The influence of organizational culture on the success of knowledge management practices with North American companies, International Business \& Economics Research Journal (IBER) 6(3): 15-28. https://doi.org/10.19030/iber.v6i3.3350

Chowdhury, S. 2005.The role of affect-and cognitions-based trust in complex knowledge sharing, Journal of Managerial Issues 17(3): 310-326.

Chuang, C. H.; Jackson, S. E.; Jiang, Y. 2016. Can knowledge-intensive teamwork be managed? Examining the roles of HRM systems, management, and tacit knowledge, Journal of Management 42(2): 524-554. https://doi.org/10.1177/0149206313478189

Elaimi, K.; Persaud, A. 2014. The impact of organizational factors and web 2.0 technologies on knowledge sharing in Saudi Arabian firms, The Journal of Human Resource and Adult Learning 10(2): $30-40$.

Empson, L. 2001. Fear of exploitation and fear of contamination: impediments to knowledge transfer in mergers between professional service firms, Human Relations 54(7): 839-862. https://doi.org/10.1177/0018726701547003

Evans, M.; Dalkir, K.; Bidian, C. 2015. A holistic view of the knowledge life cycle: the knowledge management cycle (KMC) model, Electronic Journal of Knowledge Management 12(2):148-160.

Friesl, M.; Sackmann, S. A.; Kremser, S. 2011. Knowledge sharing in new organizational entities: the impact of hierarchy, organizational context, micro-politics and suspicion, Cross Cultural Management: an International Journal 18(1): 71-86. https://doi.org/10.1108/13527601111104304 
Garson, G. D. 2012. Hierarchical linear modeling: guide and applications. Sage.

Gubbins, C.; Dooley, L. 2011. Social network analysis as a tool for knowledge management for innovation, Chapter 6 in E. O'Brien, S. Clifford, M. Southern (Eds.). Knowledge management for process, organizational and marketing innovation: tools and methods. IGI Global, 95-119.

Haas, M. R.; Criscuolo, P.; George, G. 2015. Which problems to solve? Online knowledge sharing and attention allocation in organizations, Academy of Management Journal 58(3): 680-711. https://doi.org/10.5465/amj.2013.0263

Hair, J. F.; Sarstedt, M.; Pieper, T. M.; Ringle, C. M. 2012. The use of partial least squares structural equation modeling in strategic management research: a review of past practices and recommendations for future applications, Long Range Planning 45(5): 320-340.

https://doi.org/10.1016/j.lrp.2012.09.008

Holste, J. S.; Fields, D. 2010. Trust and tacit knowledge sharing and use, Journal of Knowledge Management 14(1): 128-140. https://doi.org/10.1108/13673271011015615

IBM Corp. 2016. IBM SPSS Amos Client 24.0 Microsoft Windows Multilingual, Version 24.0. NY: IBM Corp.

Ignatavičius, R.; Tvaronavičienė, M.; Piccinetti, L. 2015. Sustainable development through technology transfer networks: case of Lithuania, Journal of Security and Sustainability Issues 4(3): 261-267. https://doi.org/10.9770/jssi.2015.4.3(6)

Kuo, Y. L. 2013. Technology readiness as moderator for construction company performance, Industrial Management \& Data Systems 113(4): 558-572. https://doi.org/10.1108/02635571311322793

Kwahk, K. Y.; Park, D. H. 2016. The effects of network sharing on knowledge-sharing activities and job performance in enterprise social media environments, Computers in Human Behavior 55: 826-839. https://doi.org/10.1016/j.chb.2015.09.044

Nissen, H. A.; Evald, M. R.; Clarke, A. H. 2014. Knowledge sharing in heterogeneous teams through collaboration and cooperation: exemplified through public-private-innovation partnerships, Industrial Marketing Management 43(3): 473-482.

https://doi.org/10.1016/j.indmarman.2013.12.015

Matayong, S.; Mahmood, A.K. 2013. The review of approaches to knowledge management system studies, Journal of Knowledge Management 17(3): 472-490.

https://doi.org/10.1108/JKM-10-2012-0316

Meyer, F.; Le Fevre D. M.; Robinson, V. M. J. 2017. How ceaders communicate their vulnerability: implications for trust building, International Journal of Educational Management 31(2): 221-235. https://doi.org/10.1108/IJEM-11-2015-0150

Michailova, S.; Husted, K. 2003. Knowledge-sharing hostility in Russian firms, California Management Review 45(3): 59-77. https://doi.org/10.2307/41166176

Mueller, J. 2014. A specific knowledge culture: cultural antecedents for knowledge sharing between project teams, European Management Journal 32(2): 190-202.

https://doi.org/10.1016/j.emj.2013.05.006

Pervaiz, U.; Imran, M.; Arshad, Q.; Haq, R.; Khan, M. K. 2016. Human resource practices and knowledge sharing: the moderating role of trust, International Journal of Organizational Leadership 5(1): 15-23.

Pinjani, P.; Palvia, P. 2013. Trust and knowledge sharing in diverse global virtual teams, Information \& Management 50(4): 144-153. https://doi.org/10.1016/j.im.2012.10.002

Polanyi, M. 1966. The tacit dimension. New York: Doubleday.

Raudeliūnienè, J.; Tvaronavičienè, M.; Dzemyda, I. 2014. Towards economic security and sustainability: key success factors of sustainable entrepreneurship in conditions of global economy, Journal of Security and Sustainability Issues 3(4): 71-79. https://doi.org/10.9770/jssi.2014.3.4(7) 
Raes, E.; Kyndt, E.; Decuyper, S.; Van den Bossche, P.; Dochy, F. 2015. An exploratory study of group development and team learning, Human Resource Development Quarterly 26(1): 5-30. https://doi.org/10.1002/hrdq.21201

Renzl, B. 2008. Trust in management and knowledge sharing: the mediating effects of fear and knowledge documentation, The International Journal of Management Science 36(2): 206-220. https://doi.org/10.1016/j.omega.2006.06.005

Rosendaal, B.; Bijlsma-Frankema, K. 2015. Knowledge sharing within teams: enabling and constraining factors, Knowledge Management Research \& Practice 13(3): 235-247. https://doi.org/10.1057/kmrp.2013.45

Saris, W. E.; Revilla, M. 2016. Correction for measurement errors in survey research: necessary and possible, Social Indicators Research 126(3): 1005-1020.

https://doi.org/10.1007/s11205-015-1002-X

Schreiber, J. B.; Nora, A.; Stage, F. K.; Barlow, E. A.; King, J. 2006. Reporting structural equation modeling and confirmatory factor analysis results: a review, The Journal of Educational Research 99(6): 323-338. https://doi.org/10.3200/JOER.99.6.323-338

Serenko, A.; Serenko, A.; Bontis, N.; Bontis, N. 2016. Negotiate, reciprocate, or cooperate? The impact of exchange modes on inter-employee knowledge sharing, Journal of Knowledge Management 20(4): 687-712. https://doi.org/10.1108/JKM-10-2015-0394

Stuermer, M.; Abu-Tayeh, G.; Myrach, T. 2016. Digital sustainability: basic conditions for sustainable digital artifacts and their ecosystems, Sustainability Science 12(2): 247-262.

https://doi.org/10.1007/s11625-016-0412-2

Un, C. A.; Asakawa, K. 2015. Types of R\&D collaborations and process innovation: the benefit of collaborating upstream in the knowledge chain, Journal of Product Innovation Management 32(1): 138-153. https://doi.org/10.1111/jpim.12229

Wang, S.; Noe, R. A.; Wang, Z. M. 2014. Motivating knowledge sharing in knowledge management systems: a quasi-field experiment, Journal of Management 40(4): 978-1009.

https://doi.org/10.1177/0149206311412192

Wasko, M.; Faraj, S. 2005 Why should I share? Examining social capital and knowledge contribution in electronic networks of practice, MIS Quarterly 29(1): 35-57.

Wiersma, W. (Ed.). 2000. Research methods in education: an introduction. Allyn \& Bacon.

Zhou, K. Z.; Li, C. B. 2012. How knowledge affects radical innovation: knowledge base, market knowledge acquisition, and internal knowledge sharing, Strategic Management Journal 33(9): 1090-1102. https://doi.org/10.1002/smj.1959 

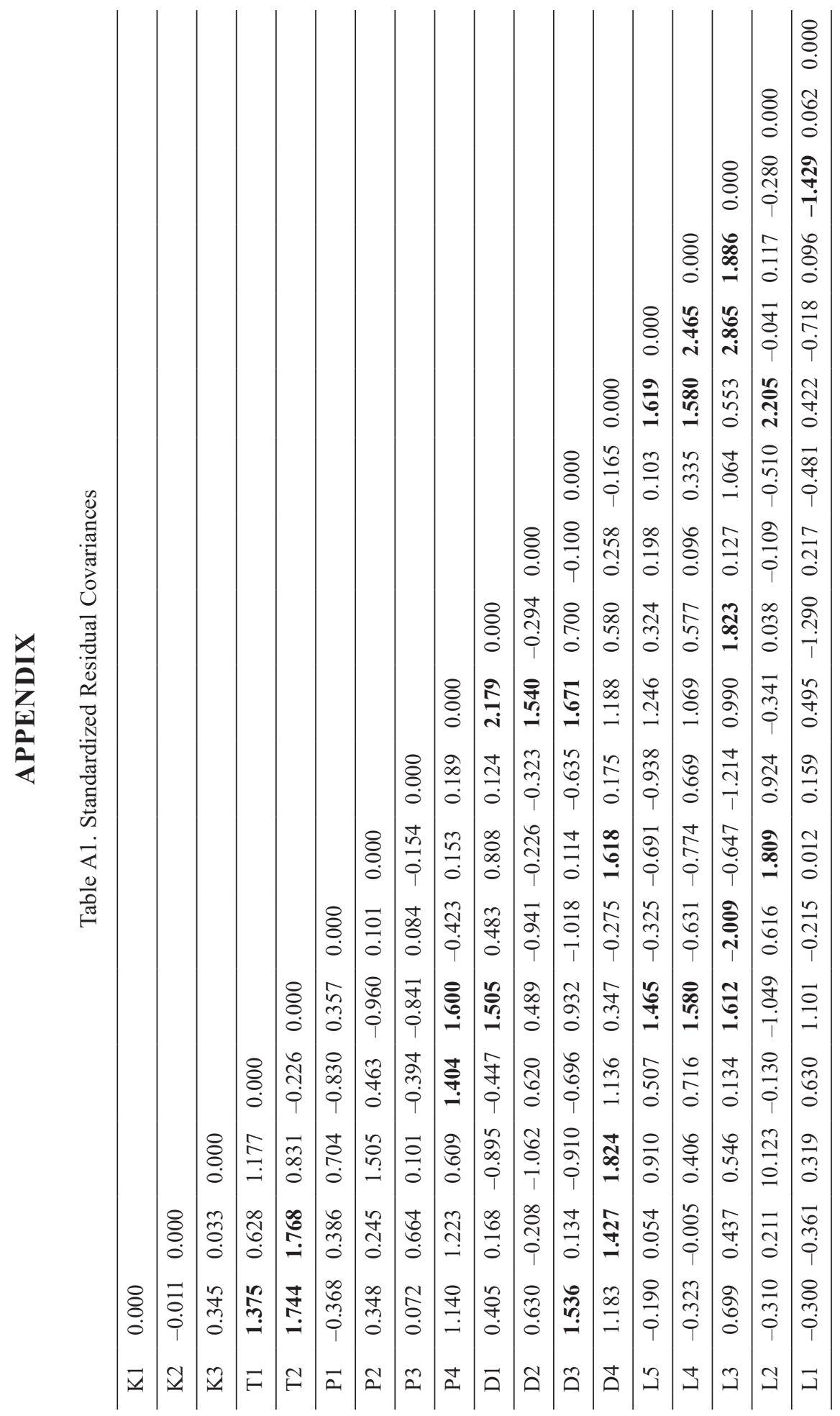
Rasa SMALIUKIENĖ. Dr, Professor at Gen. J. Žemaitis Military Academy of Lithuania and Associated Professor at Vilnius Gediminas Technical University, author of more than 50 publications. Her research interests focus on knowledge management and communication, human resource management and leadership.

Svajonė BEKEŠIENĖ. Dr, Associate Professor at Gen. J. Žemaitis Military Academy of Lithuania, Department of Engineering Management, author of over 50 papers published in national and international journals. Her research interests are in scientific computing, mathematical modelling, and human resource management.

Eugenijus CHLIVICKAS. Professor at the Department of International Economics and Management Department, Vilnius Gediminas Technical University, author of over 200 scientific and methodological works and publications in the country and abroad. His research interests are: human resources management in business and public sectors, knowledge management and organizational behavior.

Marius MAGYLA. Military officer and MSc in human resource management. His research area is knowledge management. 